\title{
HIPERFIBRINÓLISE EVIDENCIADA PELA TROMBOELASTOMETRIA DURANTE TRANSPLANTE HEPÁTICO ORTOTÓPICO
}

\author{
Hyperfibrinolysis evidenced by thromboelastometry during \\ orthotopic liver transplantation
}

José Carlos Rodrigues Nascimento ${ }^{1}$, Antonio Tiago Mota Pinheiro², Jéssica Silva Miranda², Ivelise Canito Brasil",

Tayná de Lima Freire ${ }^{2}$, Anderson Emanuel Caliope Castelo Branco Mourão

\section{IMAGEM}

\section{Instituição:}

1 Unidade de Transplante Hepático do Hospital Geral de Fortaleza HGF, Fortaleza/CE - Brasil.

2 Residentes de Anestesiologia do Hospital Geral de Fortaleza - HGF, Fortaleza/CE - Brasil.

\section{Correspondência:}

José Carlos Rodrigues Nascimento

Rua Antonele Bezerra, 280, APT 202, CEP 60160-070, Meireles, Fortaleza/CE

Tel.: (85) 99668-8500

E-mail: jcr.nascimento@hotmail.com
Aceito em: 19/12/3013

\section{DISCUSSÃO}

No transplante hepático, a hiperfibrinólise acontece predominantemente durante a fase anepática e pósreperfusão, e é mais comum no paciente cirrótico, devido ao aumento dos níveis do ativador do plasminogênio tipotecidual (t-PA) que é o mais importante ativador endógeno do plasminogênio. Nesse sentido, antifibrinolíticos são administrados no perioperatório com o propósito de melhorar a hemostasia e reduzir as necessidades de transfusão sanguínea. ${ }^{1-3}$

No estudo de Hu et al. a hiperfibrinólise foi observada em $31,3 \%$ dos pacientes cirróticos, estando correlacionado com escore Child-Pugh mais alto e com alterações laboratoriais (tempo de tromboplastina parcial ativada, tempo de protrombina, contagem de plaquetas, nível de fibrinogênio e hiperbilirrubinemia.) $)^{2}$

No início da cirurgia, o tromboelastograma mostrou-se normal (Figura 1).

$\mathrm{Na}$ fase anepática e sem o uso de antifibrinolítico, diagnosticou-se hiperfibrinólise pela tromboelastometria (Figura 2).

Então, foram administradas $50 \mathrm{mg} . \mathrm{kg}$ de ácido épsilon aminocapróico, no total de $3 \mathrm{~g}$ em 30 minutos, com repetição da tromboelastometria após término da infusão, que mostrou correção da hiperfibrinólise (Figura 3). 


\section{IMAGEM DA TROMBOELASTOMETRIA DURANTE TRANSPLANTE HEPÁTICO}

Figura 1 - Extem, no início do transplante hepático

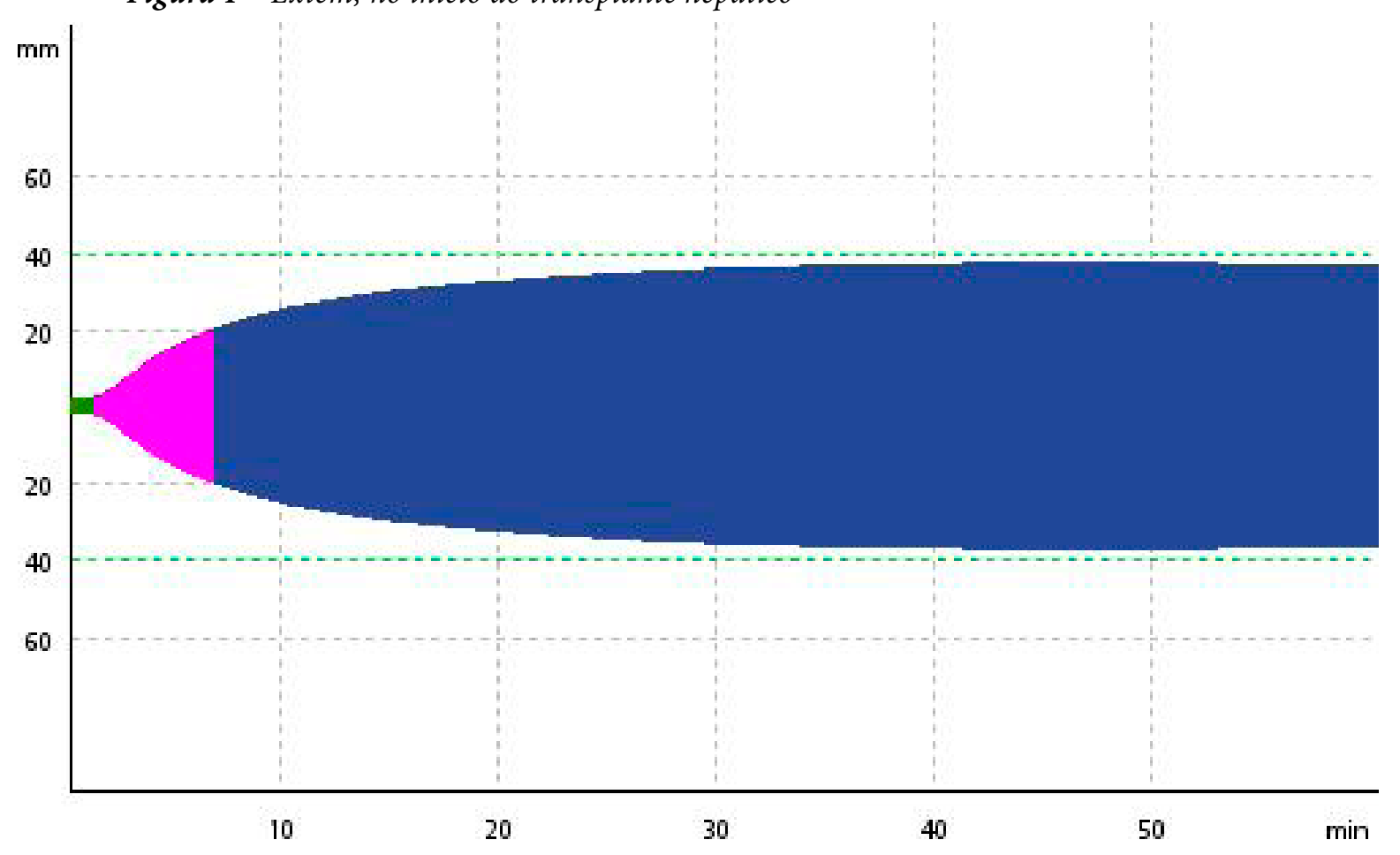

Figura 2 - Extem, na fase anepática: hiperfibrinólise

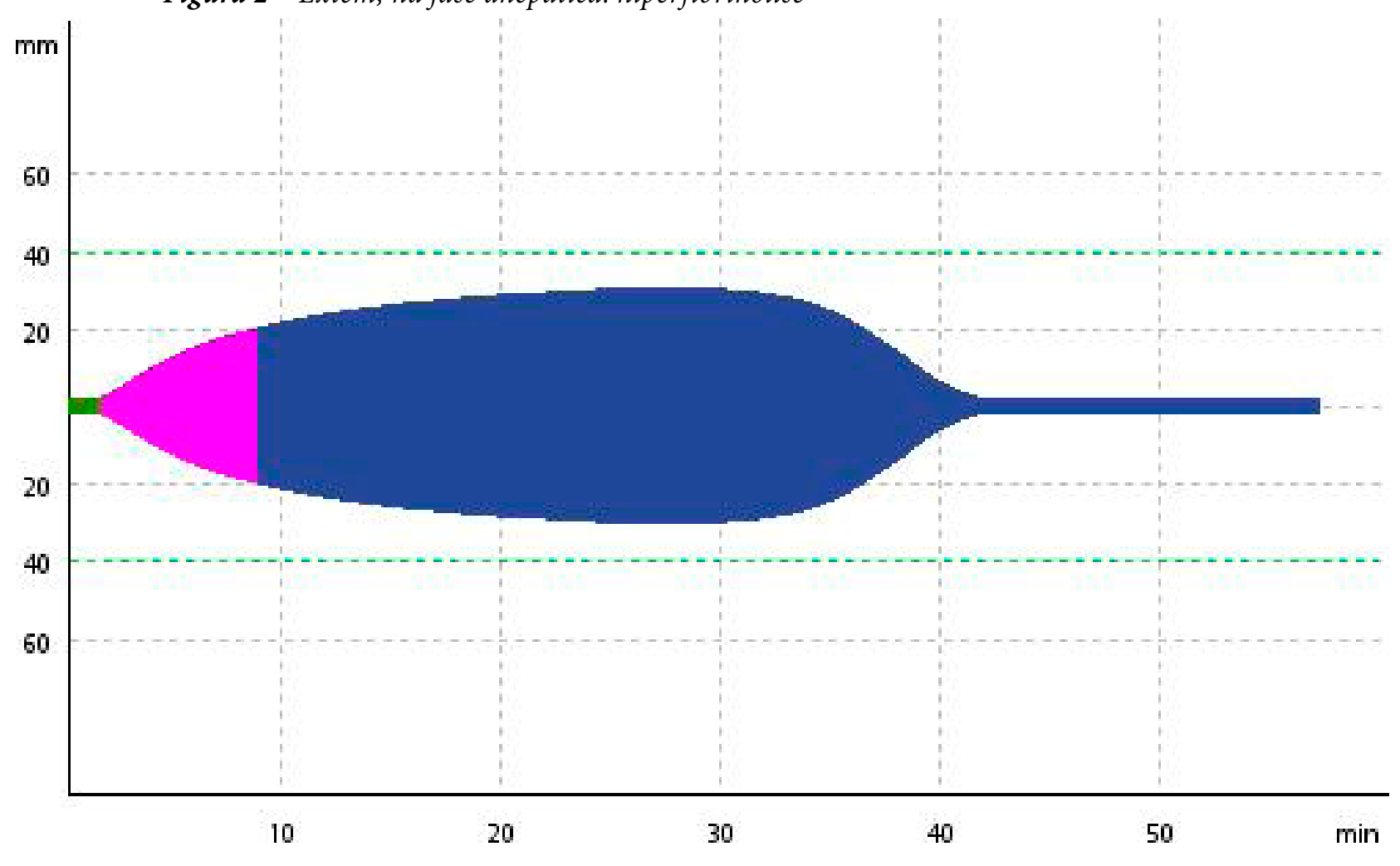




\section{IMAGEM DA TROMBOELASTOMETRIA DURANTE TRANSPLANTE HEPÁTICO}

Figura 3 - Extem, após correção da hoperfibrinólise com ácido épsilon aminocapróico

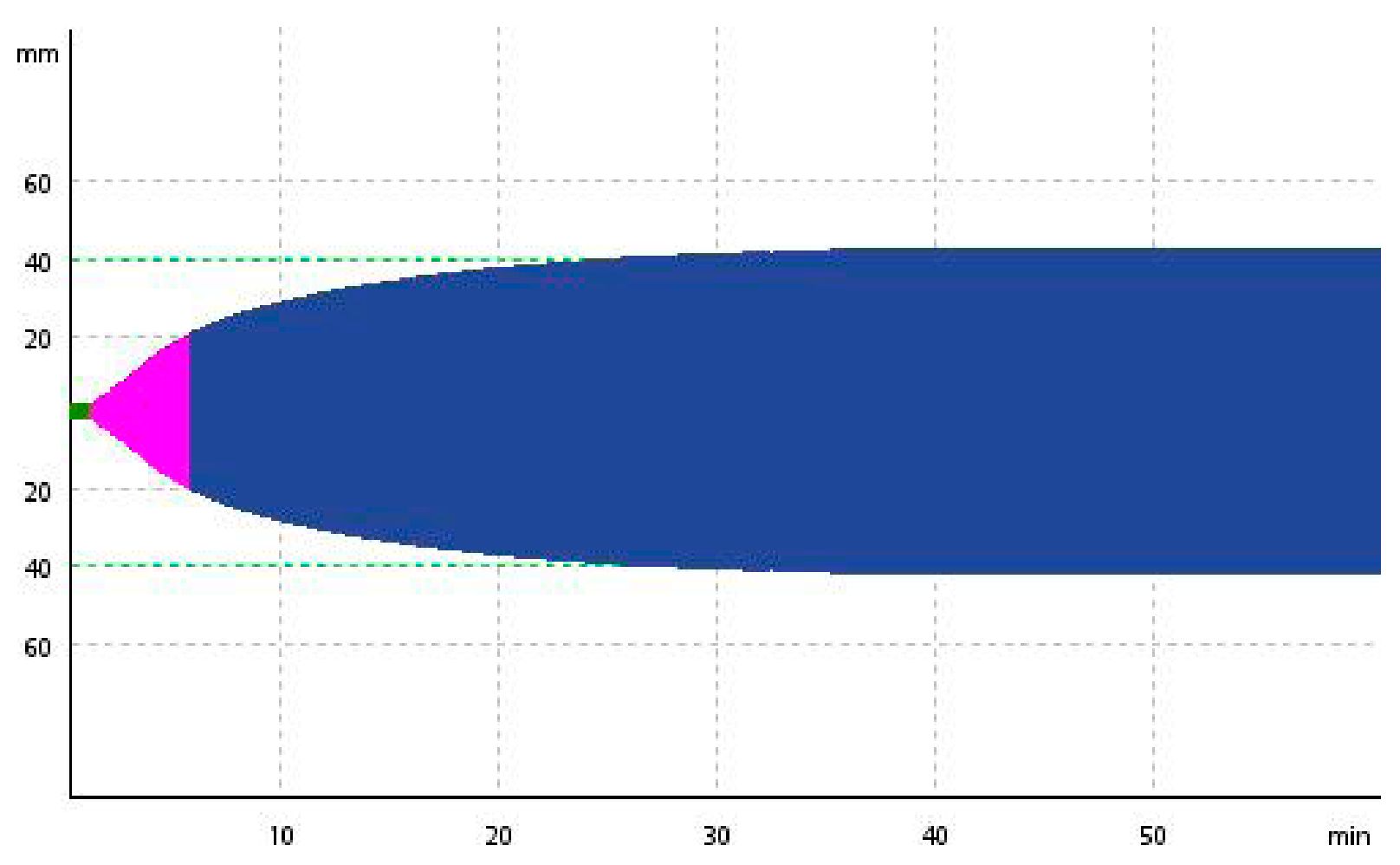

\section{REFERÊNCIAS}

1. Molenaar IQ et al. Efficacy and Safety of Antifibrinolytic Drugs in Liver Transplantation: A Systematic Review and Meta-Analysis. American Journal of Transplantation. 2007;7:185-94.

2. Hu et al. Hyperfibrinolytic Activity in Hospitalized Cirrhotic Patients in a Referral Liver Unit. Am J Gastroenterol. 2001;96(5):1581-6.

3. Ortmann E, Besser MW, Klein AA. Antifibrinolytic agents in current anaesthetic practice. Br J Anaesth. 2013;111(4): 549-63. 